\title{
ERRATUM
}

\section{Enamel hypoplasia and dental wear of North American late Pleistocene horses and bison: an assessment of nutritionally based extinction models - ERRATUM}

\author{
Christina I. Barrón-Ortiz, Christopher N. Jass, Raúl Barrón-Corvera, Jennifer Austen, \\ and Jessica M. Theodor
}

DOI: $10.1017 /$ pab.2019.17

In the original publication of Barrón-Ortiz et al. (2019), Table 10 had incorrect $t$ and $p$ values for the Bluefish Caves Equus "ferus" locality and species. The correct values are $t=-4.062$ and $p=0.0000$. The corrected table is replicated below.

The publisher apologizes for the error.

\section{Literature Cited}

Barrón-Ortiz, C. I., C. N. Jass, R. Barrón-Corvera, J. Austen, and J. M. Theodor. 2019. Enamel hypoplasia and dental wear of North American late Pleistocene horses and bison: an assessment of nutritionally based extinction models. Paleobiology, doi: 10.1017/pab.2019.17.

TABLE 10. Results of $t$-tests (left-tailed) using the bootstrap resampling method (10,000 replicates) to determine whether the number of stress events per affected specimen increased during the postglacial relative to the previous time interval(s). $n \mathrm{H}=$ total number of specimens with enamel hypoplasia; $\mathrm{ME}=$ mean number of hypoplastic events per affected specimen; $t=t$-statistic; $p=p$-value. Statistically significant $p$-values are shown in bold. An asterisk $\left({ }^{*}\right)$ identifies comparisons in which the mean number of hypoplastic events per affected specimen significantly decreased during the postglacial (i.e., showing a trend opposite to the one being tested). "Equus conversidens" from the American Southwest for the full-glacial interval was excluded from the analysis because of its small sample size.

\begin{tabular}{|c|c|c|c|c|c|}
\hline Locality and species & Time interval comparisons & $n \mathrm{H}$ & ME & $t$ & $p$ \\
\hline \multirow[t]{2}{*}{ Bluefish Caves Equus "ferus" } & Preglacial/Full-glacial & 9 & 1.33 & \multirow[t]{2}{*}{-4.062} & \multirow[t]{2}{*}{0.0000} \\
\hline & Postglacial & 7 & 3.43 & & \\
\hline Alberta & Preglacial & 65 & 2.16 & \multirow[t]{2}{*}{2.338} & \multirow[t]{2}{*}{$0.9894^{*}$} \\
\hline E. "ferus" & Postglacial & 9 & 1.37 & & \\
\hline Alberta & Preglacial & 9 & 1.31 & \multirow[t]{2}{*}{0.029} & \multirow[t]{2}{*}{0.5287} \\
\hline Bison sp. & Postglacial & 10 & 1.30 & & \\
\hline American Southwest & Preglacial & 15 & 1.23 & \multirow[t]{2}{*}{-1.963} & \multirow{2}{*}{0.0297} \\
\hline "Equus conversidens" & Postglacial & 16 & 1.78 & & \\
\hline \multirow{2}{*}{ American Southwest E. "ferus" } & Full-glacial & 5 & 1.60 & \multirow[t]{2}{*}{-2.246} & \multirow[t]{2}{*}{0.0437} \\
\hline & Postglacial & 30 & 2.30 & & \\
\hline
\end{tabular}

